\title{
Estágios imaturos e bionomia de Cyclomia mopsaria Guenée (Lepidoptera, Geometridae) ${ }^{1}$
}

\author{
Gláucia Marconato² \& Manoel Martins Dias ${ }^{3}$
}

${ }^{1}$ Realizado com auxílio do Programa BIOTA/FAPESP.

${ }^{2}$ Bolsista CAPES. Endereço eletrônico: glaucia.m@itelefonica.com.br

${ }^{3}$ Departamento de Ecologia e Biologia Evolutiva, Universidade Federal de São Carlos. Caixa Postal 676, 13565-905 São Carlos-SP, Brasil. Endereço eletrônico: manoelmd@ power.ufscar.br

\begin{abstract}
Immature stages and bionomics of Cyclomia mopsaria Guenée (Lepidoptera, Geometridae). Data on the immature stages and bionomics of Cyclomia mopsaria Guenée, [1858] are presented. The material was collected in São Carlos, São Paulo, Brazil. The larvae fed on Erythroxylum microphyllum St.-Hilaire (Erythroxylaceae).
\end{abstract}

KeYwords. Cyclomia mopsaria; Erythroxylum microphyllum; Geometridae; immature stages; Lepidoptera.

Resumo. Dados sobre estágios imaturos e bionomia de Cyclomia mopsaria Guenée, [1858] são apresentados. O material procede de São Carlos, São Paulo, Brasil. As larvas alimentaram-se de Erythroxylum microphyllum St.-Hilaire (Erythroxylaceae).

Palavras-Chave. Cyclomia mopsaria; Erythroxylum microphyllum; estágios imaturos; Geometridae; Lepidoptera.

Os estágios imaturos de Cyclomia mopsaria Guenée, [1858] foram estudados com base em material procedente de São Carlos (Campus da Universidade Federal), São Paulo. Larvas foram obtidas em Erythroxylum microphyllum St.-Hilaire (Erythroxylaceae), em área de cerrado, contígua à pequena mata ciliar. O gênero Cyclomia Guenée, [1858] compreende espécies neotropicais (PITKIN 2002) das quais nada se conhece sobre a morfologia dos estágios imaturos. BECKER \& MiLleR (2002) referiram-se à variabilidade dos adultos de C. mopsaria na ilha de Guana (Ilhas Virgens, Antilhas); também constatamos variação no material estudado, envolvendo linhas e máculas das asas (Figs. 28-31).

Diniz \& Morais (1995, 1997), Milhomen et al. (1997) e Diniz et al. (2001) citaram larvas de C. mopsaria sobre Erythroxylum deciduum St.-Hilaire e Erythroxylum tortuosum Martius, plantas de cerrado, no Brasil central. Morais et al. (1999) mencionaram, para essa mesma região, larvas de C. mopsaria com ocorrência de janeiro a agosto, novembro e dezembro; o período pupal foi de 11,1 dias, em média, em qualquer época do ano. Milhomen et al. (1997) referiram-se a larvas de lepidópteros exclusivas de Erythroxylum spp., das quais $C$. mopsaria representou $7 \%$. DinIZ \& MORAIS (1995) referiramse também a Cyclomia ocana Schaus, 1901 sobre E. deciduum e E. tortuosum. Brunner et al. (1975) apud BeCKER \& MiLLER (2002) referiram-se a Erythroxylum havanense Jacq. como planta hospedeira de Cyclomia sp. em Cuba.

$\mathrm{O}$ material estudado encontra-se depositado no Departamento de Ecologia e Biologia Evolutiva, Universidade Federal de São Carlos.

\section{ESTÁGIOS IMATUROS}

OVO. Comprimento, 0,54-0,58 mm; largura, 0,32 - 0,36 mm; espessura, 0,28 - 0,30 mm. Oblongo, com extremidade micropilar achatada e um pouco mais larga que a extremidade oposta. Amarelo-esverdeado claro, quando posto; após o segundo dia torna-se amarelo, com manchas vermelhas em posição e forma variáveis; na maioria surge inicialmente uma mancha vermelha na extremidade micropilar.

LARVA. Primeiro ínstar. Comprimento, 4, $1 \mathrm{~mm}$; largura da cápsula cefálica, $0,22-0,24 \mathrm{~mm}$. Cápsula cefálica verdeclara; faixa central castanha desde o clípeo até o vértice; lateralmente, outra faixa castanha envolve os estemas e a parte inferior dos epicrânios, junto à base das antenas; labro e mandíbulas também castanhos. Tegumento verde-claro, com faixa castanho-escura dorsal longitudinal, contínua com a faixa cefálica central, terminando no escudo supra-anal; de cada lado, outra faixa castanha semelhante, contínua com a faixa cefálica lateral, vai até a base das pernas anais. Escudos verdeclaros: cervical com faixa central castanho-escura acinzentada; supra-anal com faixa castanho-escura central; para-anais com faixa cinzenta na margem anterior. Espiráculos verde-claros, com peritrema castanho, localizados na borda dorsal da faixa castanha lateral. Pernas torácicas verde-claras.

Segundo ínstar. Comprimento, $6,9 \mathrm{~mm}$; largura da cápsula cefálica, 0,33-0,36 mm. Cápsula cefálica verde-clara com manchas irregulares levemente acastanhadas, dispersas e pouco nítidas; faixa central castanha, do clípeo ao vértice, que pode ser mais estreita e mais escura acima da fronte, se comparada àquela de larvas de primeiro ínstar; faixa lateral que envolve os estemas e parte inferior dos epicrânios, castanho-escuras; fronte verde, com mancha castanha na parte superior, ou castanha com ângulos inferiores verdes. Tegumento verde-claro, levemente esbranquiçado, amarelado 
nas pernas abdominais; faixas castanhas, dorsal e laterais, semelhantes àquelas da larva de primeiro ínstar. Escudos verde-claros: cervical esbranquiçado, com faixa central castanha; supra-anal esbranquiçado, com faixa central castanha, difusa posteriormente; para-anais acinzentados. Espiráculos verde-claros, com peritrema castanho, localizados na faixa castanha lateral, como nas larvas de primeiro ínstar; em A8, acima da faixa. Pernas torácicas verde-amareladas.

Terceiro ínstar. (Figs. 6, 7). Comprimento, 8,9 mm; largura da cápsula cefálica, 0,50-0,58 mm. Cápsula cefálica com faixa central castanho-escura, ocupando mais da metade de cada epicrânio ou mais estreita; bordas externas dessa faixa bastante irregulares, junto a áreas esbranquiçadas e manchas amareladas, levemente acastanhadas; faixa lateral castanhoescura, envolve estemas e chega ao labro e mandíbulas, da mesma cor; fronte castanha, com ângulos inferiores verdes, ou verde com área central castanha. Tegumento verde-claroesbranquiçado; no ventre destaca-se linha branca longitudinal (apenas esboçada no segundo ínstar); faixa castanha lateral mais escura no tórax e terminando na extremidade posterior das pernas anais. Escudos: cervical verde-claroesbranquiçado, com faixa castanho-escura central; escudo lateral das pernas A6, verde-claro, com faixa estreita cinzentaclara na margem inferior, mais larga posteriormente; supraanal verde-claro-acinzentado, com faixa castanho-escura central; para-anais verde-claros, levemente acinzentados. Espiráculos amarelado-claros, com peritrema castanho, dispostos em relação à faixa castanha lateral conforme descrito para o segundo ínstar. Pernas torácicas verde-esbranquiçadas.

Quarto ínstar. (Figs. 3, 8, 9, 26). Comprimento, 12,8 mm; largura da cápsula cefálica, 0,81-0,9 mm. Cápsula cefálica com faixas central e laterais castanho-escuras; faixa central pode ser larga, confluente com a faixa lateral; entre ambas há áreas brancas e amareladas, de extensão variável; no vértice pode haver manchas castanho-avermelhadas, irregulares; faixa lateral castanha envolve os estemas e a parte inferior dos epicrânios; essa faixa pode ser reduzida, bem como a faixa central, esta última formando mancha no vértice (Fig. 8). Fronte amarelada, com manchas esbranquiçadas laterais e mancha castanha na parte superior; a área castanha pode ser mais ampla. Clípeo, labro e mandíbulas castanho-amarelados; as últimas com dentes castanho-escuros. Tegumento verde. Faixa castanha dorsal evidente no tórax e na extremidade do abdome; tórax com manchas castanho-escuras, pretas e amareladas; da metade posterior de A5 para trás avermelhada, com manchas amareladas; parte restante dessa faixa pouco evidente, oliváceo-acastanhada. Borda inferior da faixa dorsal e borda superior da faixa lateral (citadas nas larvas de ínstares anteriores) marcadas por linha branca irregular, mais aparente nas extremidades anterior e posterior da larva. Linha branca inferior mais nítida logo acima de cada espiráculo, expandida em mancha branca irregular. Faixa castanha lateral evidente no tórax e na extremidade do abdome (A8 para trás); parte restante da faixa pouco evidente e amarelada, interrompida entre os espiráculos pela cor verde do tegumento; no tórax e abdome com manchas castanho-amareladas ou avermelhadas e, na extremidade do abdome, com manchas castanho-amareladas amplas ao redor dos espiráculos; algumas larvas têm faixa lateral castanho-escura evidente ao longo de todo o corpo, alargada no abdome antes dos espiráculos, estes rodeados por mancha amarela (Fig. 26). Tegumento ventral verdeesbranquiçado, com fileira mediana de manchas brancoamareladas irregulares. Escudos: cervical castanho na área central e branco nas laterais; supra-anal castanho-avermelhado na faixa central, com manchas amareladas e áreas laterais brancas; para-anais esbranquiçados, com manchas castanhas. Pernas A6 amarelado-claras, esverdeadas; escudo amarelado, com manchas avermelhadas, irregulares. Espiráculos castanhoamarelados, com peritrema castanho-escuro. Pernas torácicas amareladas, com manchas esbranquiçadas na coxa e fêmur; algumas larvas têm pernas metatorácicas com mácula castanhoescura na face posterior do fêmur, ou este castanho-escuro e artículos apicais castanho-claro-amarelados.

Quinto ínstar.(Figs. 1, 2, 4, 5, 10, 11, 20-25). Comprimento, 25,2 mm; largura da cápsula cefálica, 1,28-1,5 mm. Cápsula cefálica castanho-clara, com manchas esbranquiçadas; área castanho-escura na parte anterior e vértice, com pontos pretos reunidos em máculas; essa área tem contornos irregulares, amplitude variável e forma, geralmente, uma faixa transversal ao nível da parte superior da fronte; áreas laterais dos epicrânios com pontos castanhos ou pretos, agrupados em manchas alongadas; estemas envolvidos por mancha castanho-escura. Fronte castanho-clara, com área castanhoescura na parte superior, mais ou menos ampla; parte inferior pode ser acinzentada. Adfrontes castanho-claras, geralmente com manchas castanho-escuras. Clípeo castanho-claro; labro e mandíbulas castanho-escuros, avermelhados. Antenas castanho-escuras a pretas. Tegumento castanho-acinzentado, tomado de forma variável por áreas verdes; em algumas larvas predomina a coloração verde (Fig. 25) ou castanho-escuroavermelhada, com faixa espiracular verde, intermitente; variações de coloração das larvas de quinto ínstar estão nas Figs. 20 a 25; na Fig. 23, larva castanho- olivácea com manchas amarelado-claras, semelhantes às lenticelas dos ramos da planta hospedeira. Faixas longitudinais do corpo, descritas nas larvas de ínstares anteriores, pouco distintas da coloração do tegumento; faixa dorsal amarelada, com manchas castanhoacinzentadas longitudinais, limitada lateralmente por duas linhas brancas, descontínuas e pouco definidas; faixa láterodorsal (supra-espiracular) esbranquiçada ou acinzentada, com manchas castanhas e irregulares. No abdome, de A1 a A8, ao redor dos espiráculos, área amarelada ou alaranjada, com pequena mancha preta anterior; em posição inferior e posterior ao espiráculo, mancha preta alongada. Em larvas com predominância de coloração verde há, geralmente, linha branca espiracular, evidente, dilatada em manchas aproximadamente triangulares anteriores aos espiráculos. Tegumento ventral com a mesma coloração da área dorsal, porém, mais claro e com fileira mediana de manchas amareladas irregulares; de A1 a A5 


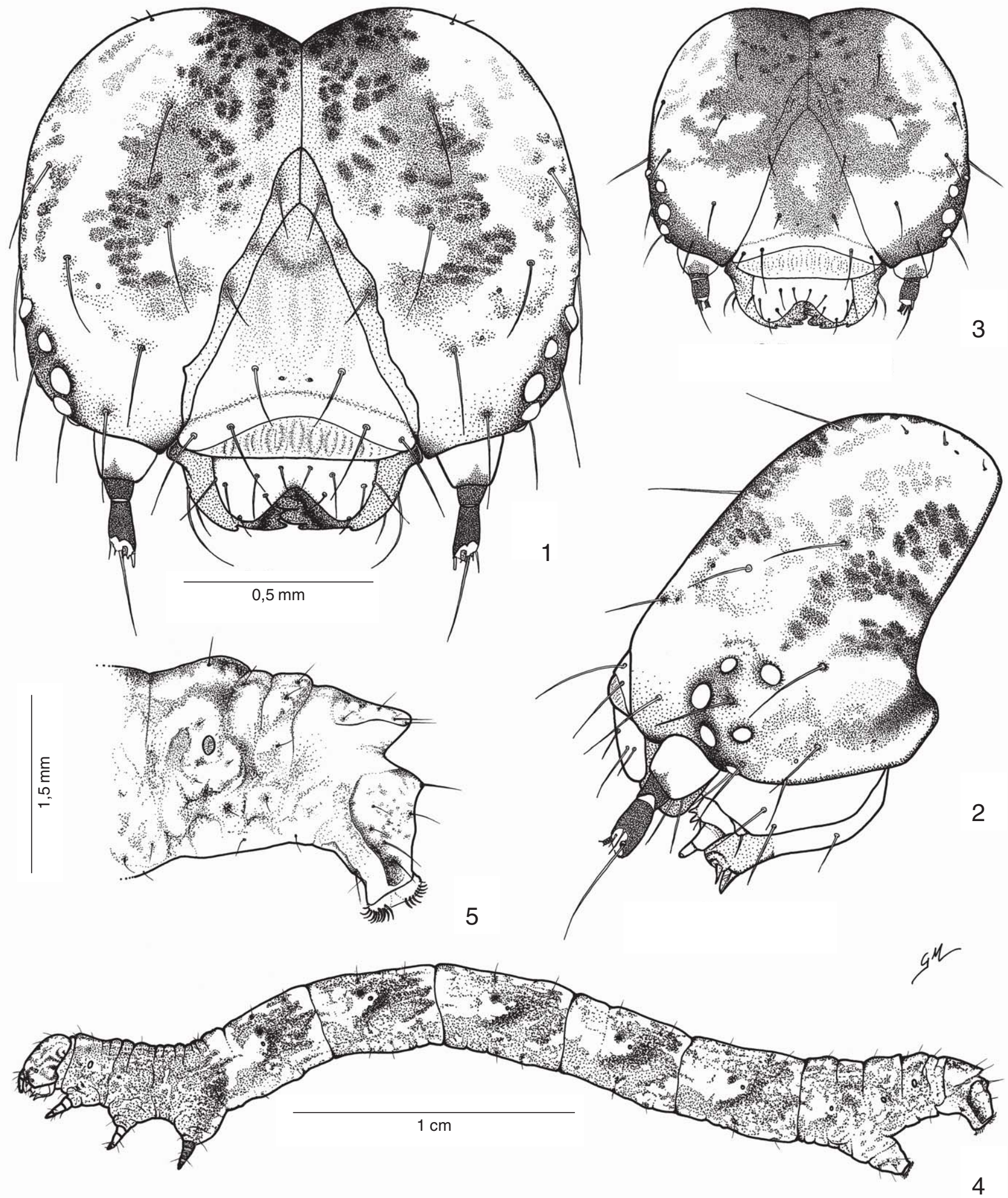

Figs. 1-5. Cyclomia mopsaria, larva. 1, cápsula cefálica, frontal, quinto ínstar; $\mathbf{2}$, idem, lateral; 3, cápsula cefálica, frontal, quarto ínstar; 4, quinto ínstar, lateral; 5, idem, extremidade do abdome. Figs. 1-3 na mesma escala. 

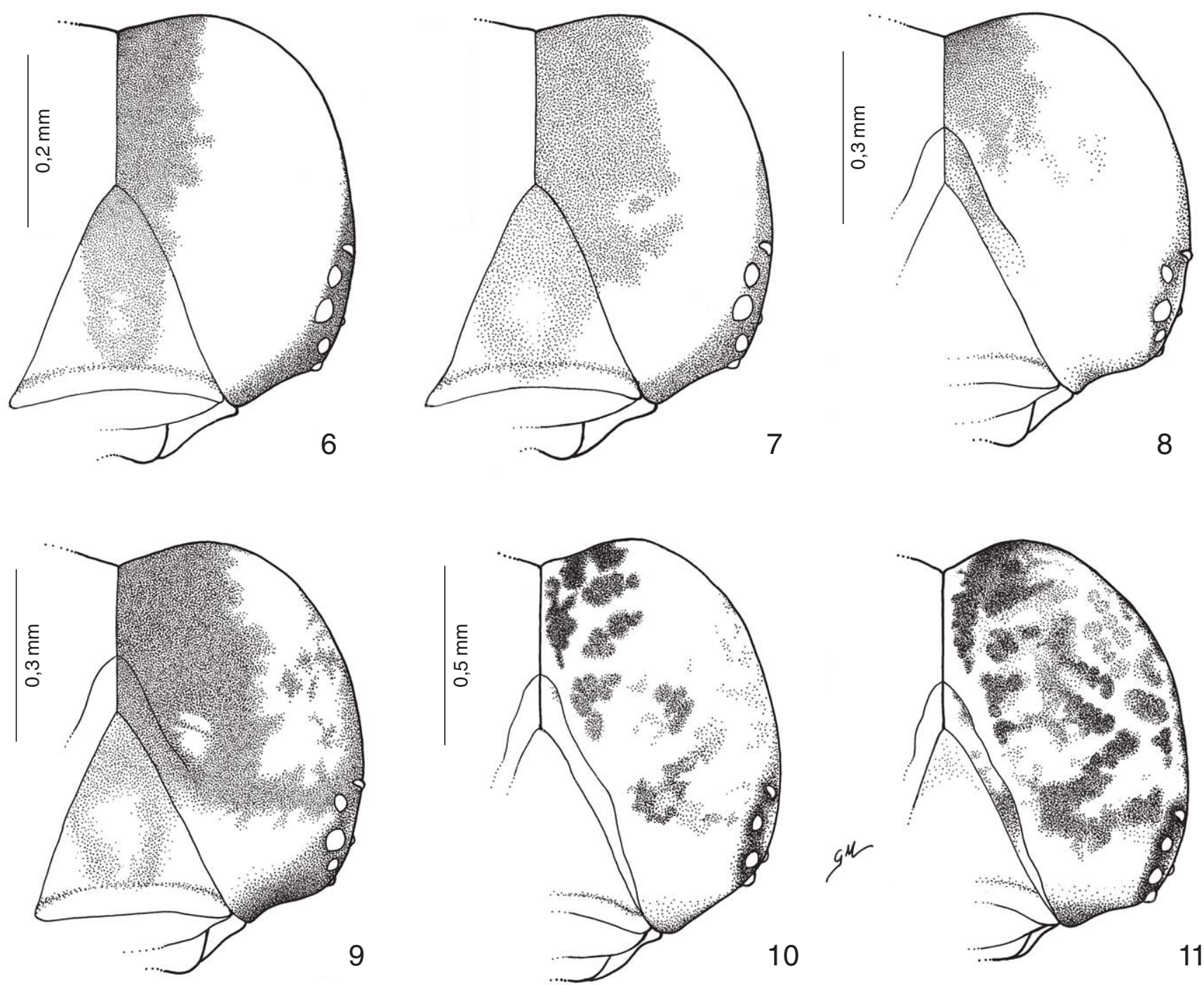

Figs. 6-11. Cyclomia mopsaria, cápsula cefálica, frontal. 6-7, terceiro ínstar; 8-9, quarto ínstar; 10-11, quinto ínstar.

uma das manchas é maior e aproximadamente central ao segmento. Escudos: cervical com faixa central castanhoacinzentada, ladeada de preto e área lateral branca, com margem externa preta; nas pernas A6, escudos esbranquiçados, com manchas róseas; supra-anal esbranquiçado, com faixa dorsal e mancha lateral arroxeado-clara; para-anais arroxeadoclaros com área esbranquiçada central e margem anterior castanho-escura. Espiráculos castanho-amarelados, com peritrema castanho-escuro. Pernas torácicas amareladas; coxa e fêmur podem ser acinzentados; pernas metatorácicas castanho-escuras externamente (Fig. 4).

PUPA. (Figs. 12-19). Comprimento, 7,7-8,4 mm. Inicialmente esverdeada, torna-se gradativamente castanha; após 12 horas, castanho-clara ou castanho-escura, sendo esta última coloração mais comum; olhos anegrados antes da emergência do adulto. Tegumento liso, com pontuação densa ou moderadamente densa nos segmentos A1 a A7, ausente na borda posterior. Vértice arredondado. Dorsalmente a A9, faixa transversal deprimida, com seis projeções dentiformes, na borda posterior. Espiráculo torácico localizado sob projeção em forma de aba da borda anterior do mesotórax. Cremaster rugoso e pontuado, com dois ganchos apicais bem desenvolvidos, inicialmente paralelos e depois curvados para os lados; lateralmente, dois pares de ganchos mais delgados, com as extremidades curvadas e mais espessadas que a base.

\section{BIONOMIA}

Os ovos são postos geralmente em fileira, ao longo da borda foliar; podem também ser postos individualmente ou em grupos de três ou quatro, no caule, na superfície do limbo foliar, no botão floral e na flor. As larvas eclodem seis dias após a oviposição e passam dois ou três dias em cada ínstar, até o quarto ínstar; o quinto ínstar dura cerca de sete ou oito 


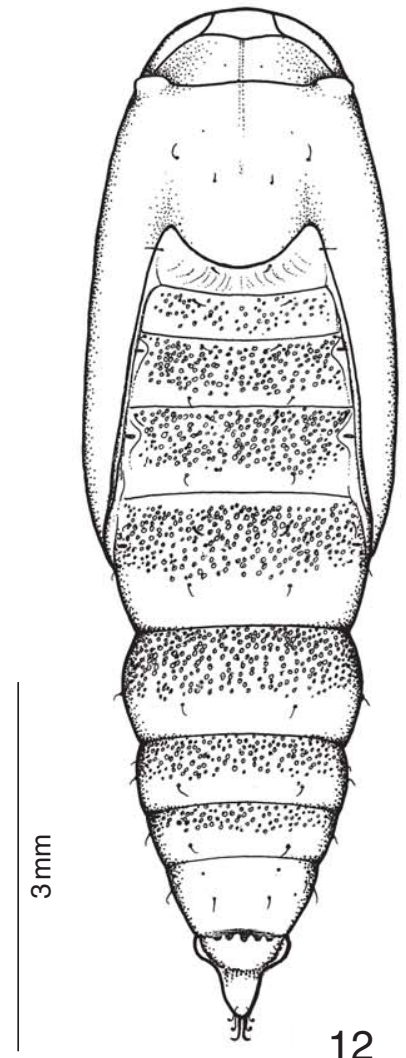

12

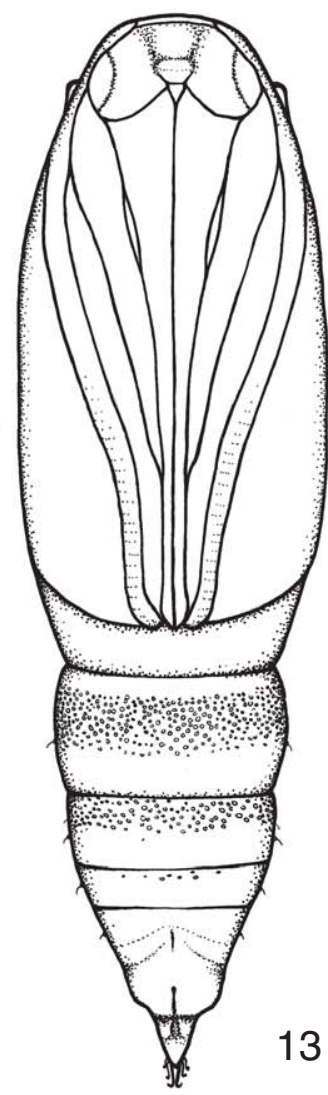

13
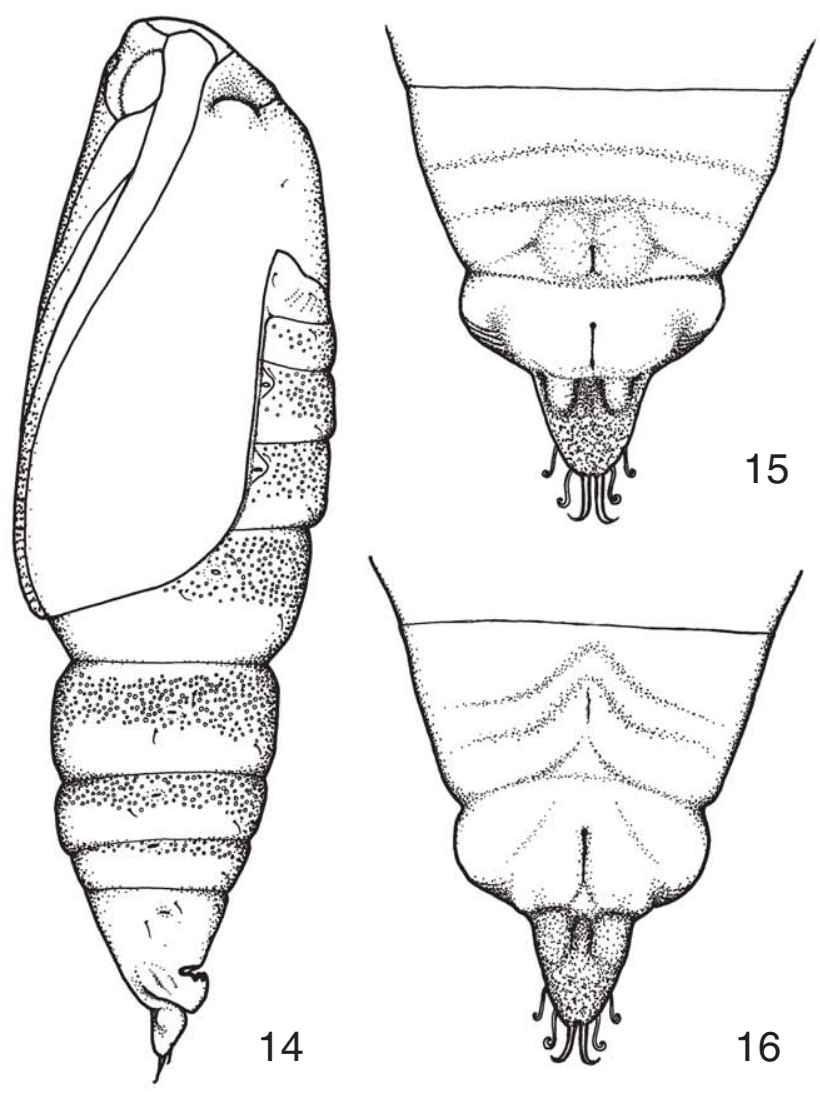
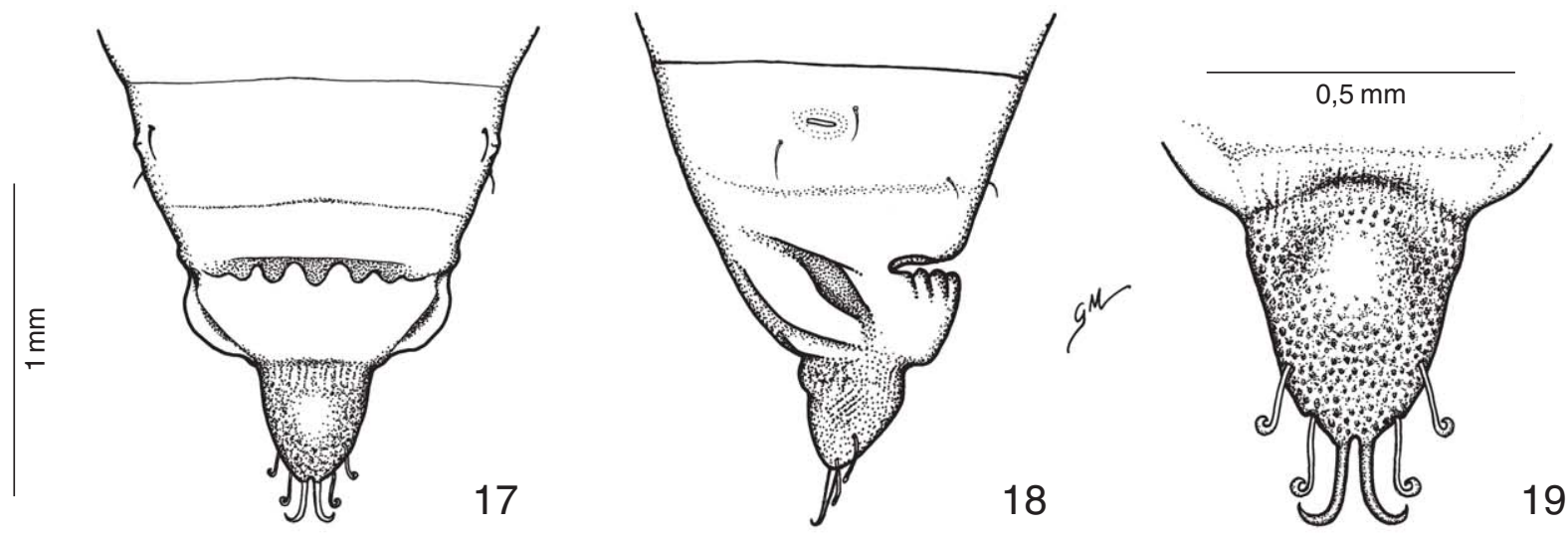

Figs. 12-19. Cyclomia mopsaria, pupa. 12, dorsal; 13, ventral; 14, lateral; 15, extremidade do abdome, ventral, macho; 16, idem, fêmea; 17, extremidade do abdome, dorsal; 18, idem, lateral; 19, cremaster, dorsal.

dias. Larvas de primeiro e segundo ínstares se alimentam da superfície das folhas e nos últimos ínstares, a partir das bordas das folhas. Quando em pré-pupa descem ao solo, onde se dá o período pupal de nove a onze dias.

Adultos em repouso mantêm as asas anteriores sobrepostas às posteriores e voltadas para trás (Fig. 27); pernas protorácicas dispostas junto ao corpo, não apoiadas no substrato; antenas colocadas juntas, voltadas para a frente e com flabelos direcionados para dentro, tocando-se nas extremidades com aqueles da antena oposta.
Quando caminham, utilizam os três pares de pernas e elevam as asas em V, deixando as posteriores parcialmente aparentes. Machos em ritual de corte movem rapidamente as antenas de forma alternada e no sentido vertical. A fêmea ovipõe no período noturno; caminha sobre a planta hospedeira tocando-a com as antenas e após, efetua a desova. Fêmeas viveram aproximadamente seis dias; machos, quatro a cinco dias.

Desenvolvimento de ovo a imago: desova, 8-9/X/2000; eclosão, 14-15/X; primeira muda, 17-18/X; segunda muda, 20- 

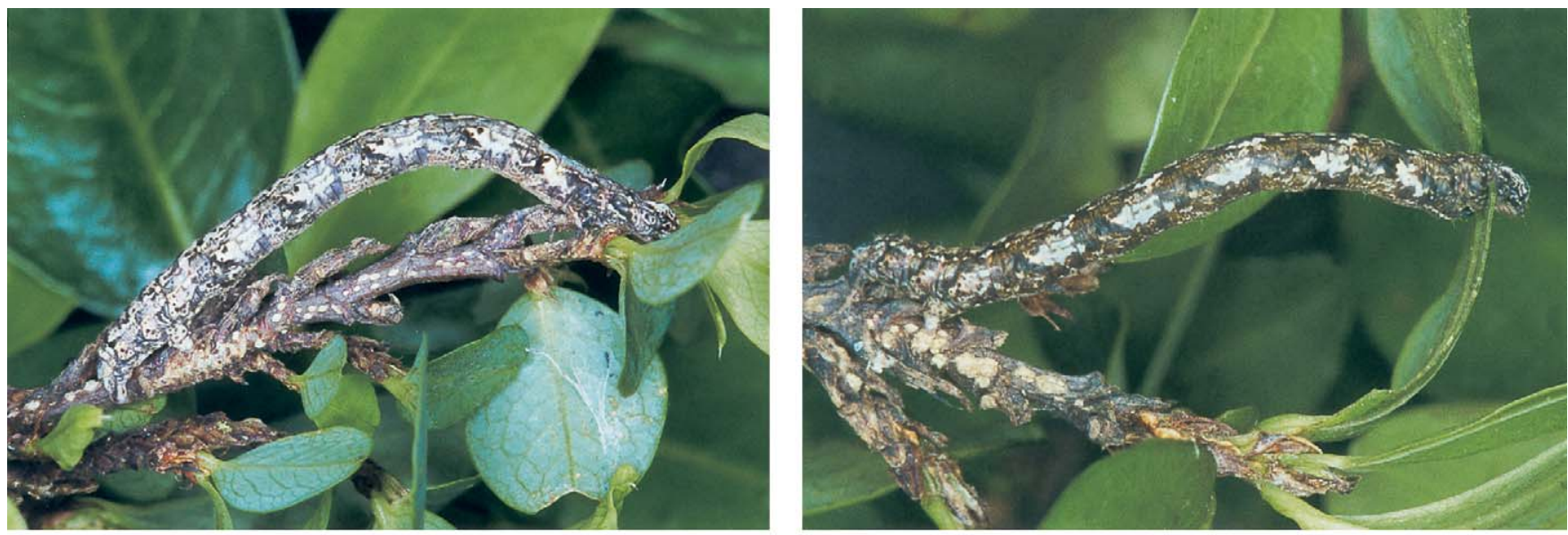

20
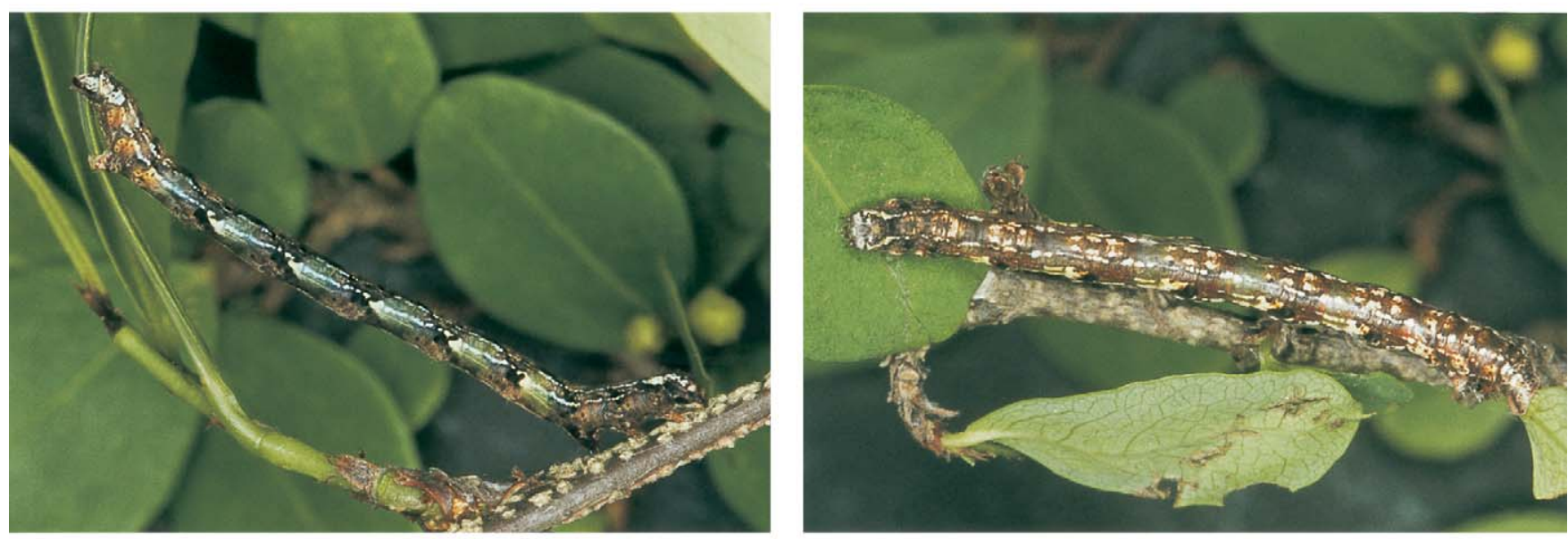

22

23
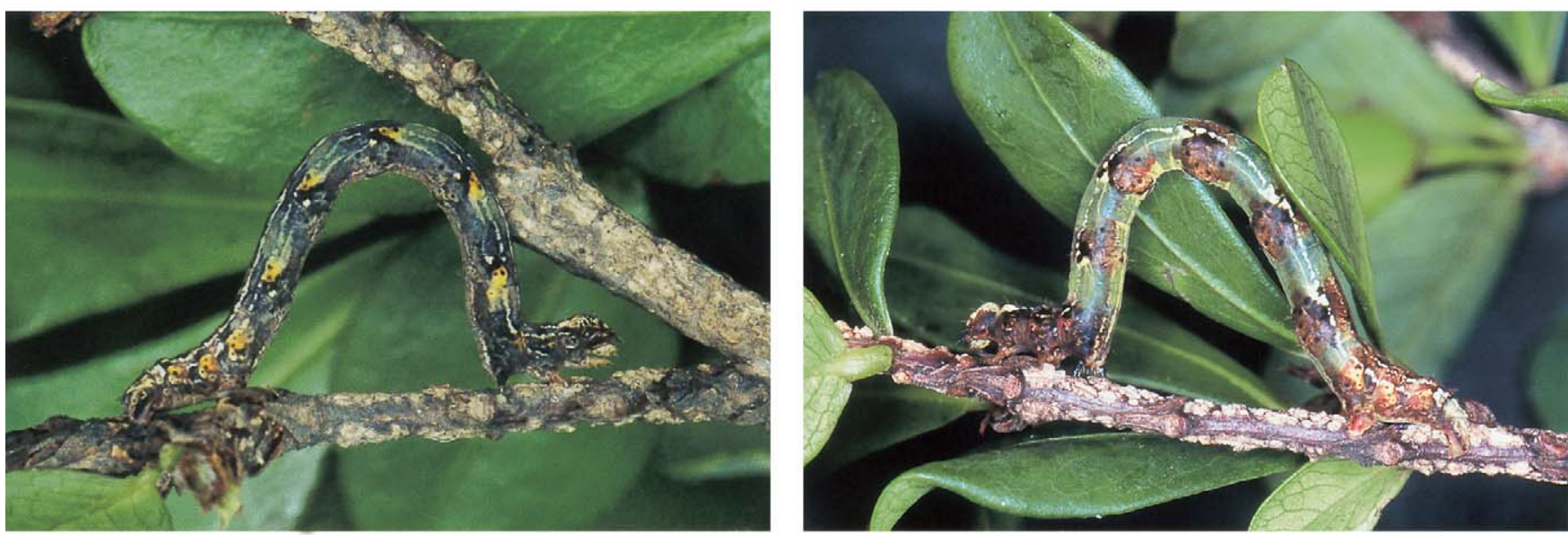

24

Figs. 20-25. Cyclomia mopsaria, larvas de quinto ínstar. 20, cinzenta-clara; 21, cinzenta-clara, com manchas castanhas; 22, verde e castanha, com faixa branca lateral; 23, castanho-olivácea, com manchas semelhantes às lenticelas da planta hospedeira; 24, castanho-escura, com áreas amarelas e verdes; 25, verde, com manchas castanhas. 

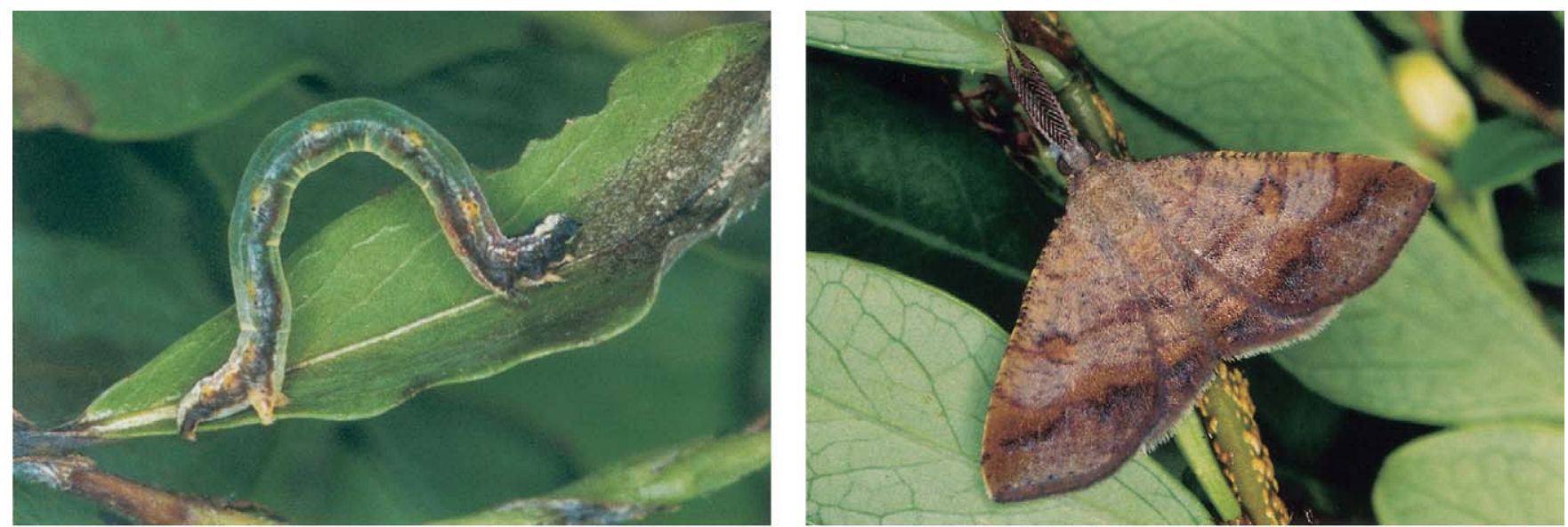

26
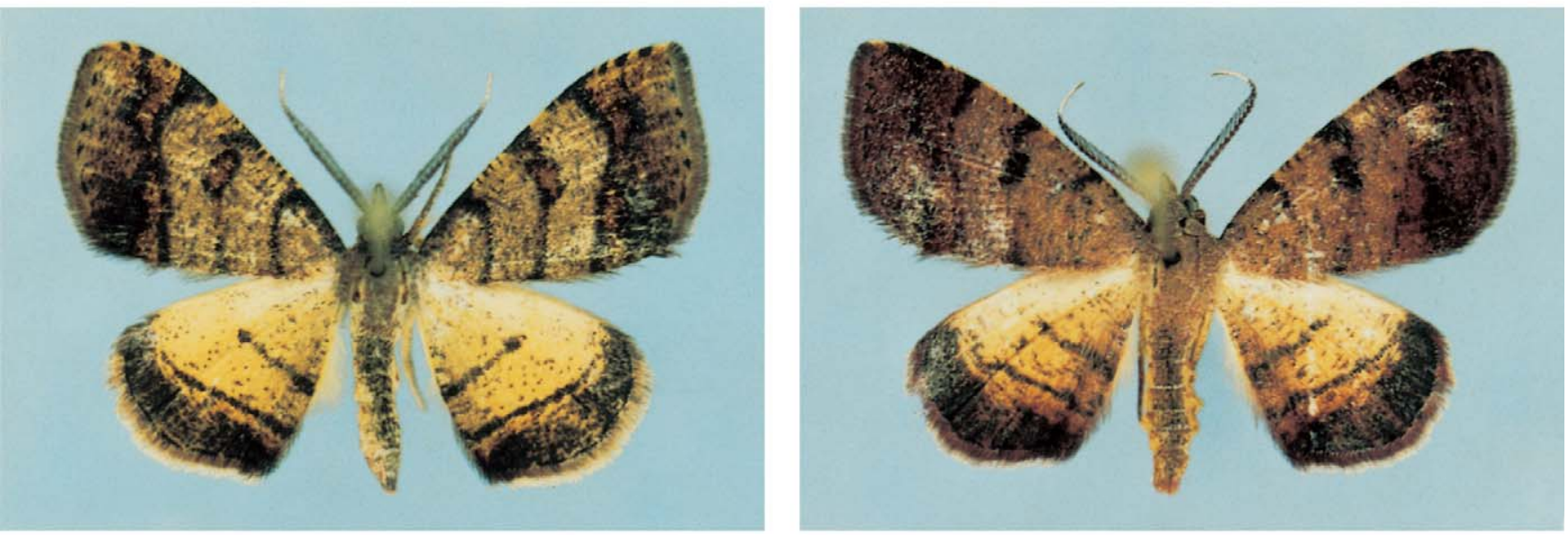

28
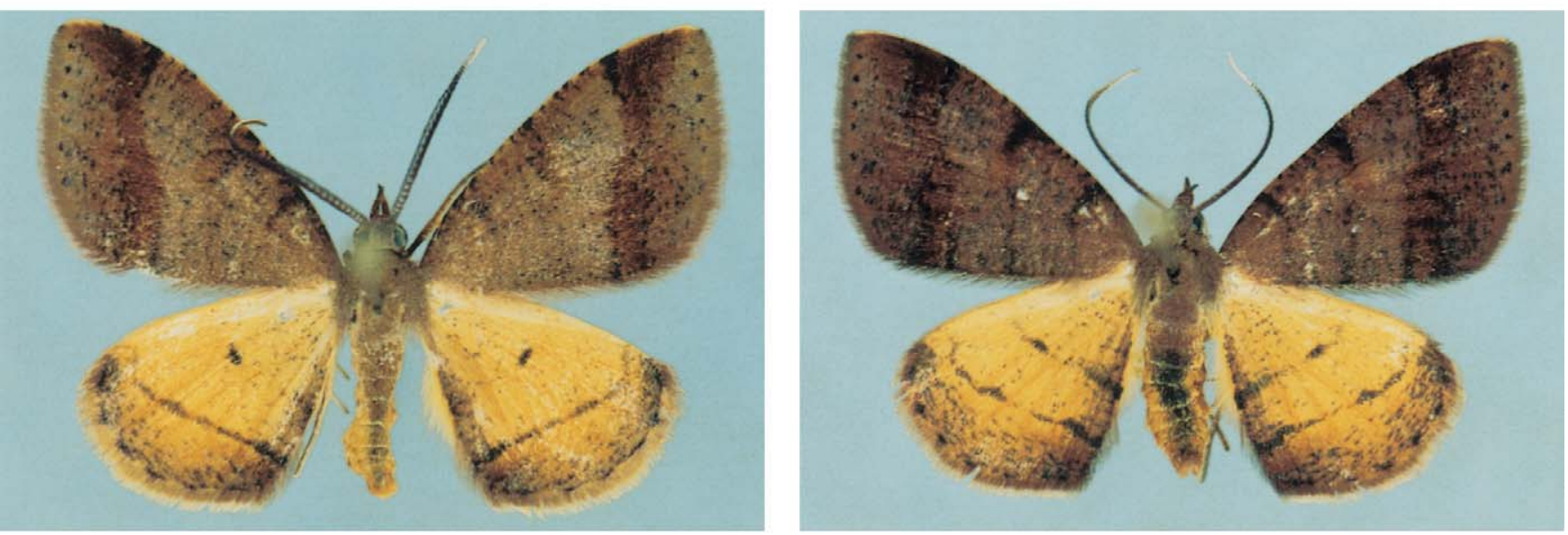

Figs. 26-31. Cyclomia mopsaria. 26, larva de quarto ínstar, lateral, forma com manchas amarelas; 27, macho em posição de repouso; 28-30, machos, variação morfológica; 31, fêmea. 
21/X; terceira muda, 22-23/X; quarta muda, 25-27/X; pupas, 1 3/XI; imagos, 10-12/ XI/2000.

Agradecimentos. À CAPES pela bolsa de Mestrado concedida. Ao Dr. Vitor O. Becker e Dr. Klaus Sattler pelo envio de fotos de tipos de espécies de Cyclomia. Ao Dr. Waldir Mantovani pela identificação da planta hospedeira.

\section{REFERÊNCIAS}

Becker, V. O. \& S. E. Miller. 2002. The large moths of Guana Island, British Virgin Islands: a survey of efficient colonizers (Sphingidae, Notodontidae, Noctuidae, Arctiidae, Geometridae, Hyblaeidae, Cossidae). Journal of the Lepidopterists' Society 56(1): 9-44.

Diniz, I. R. \& H. C. Morais. 1995. Larvas de Lepidoptera e suas plantas hospedeiras em um cerrado de Brasília, DF, Brasil. Revista Brasileira de Entomologia 39(4): 755-770.

Diniz, I. R. \& H. C. Morais. 1997. Lepidopteran caterpillar fauna of cerrado host plants. Biodiversity and Conservation 6: 817 836.

Diniz, I. R.; H. C. Morais \& A. J. A. Camargo. 2001. Host plants of lepidopteran caterpillars in the cerrado of the Distrito Federal, Brazil. Revista Brasileira de Entomologia 45(2): 107-122.

Milhomen, M. S.; H. C. Morais; I. R. Diniz \& J. D. Hay. 1997. Espécies de lagartas em Erythroxylum spp. (Erythroxylaceae) em um cerrado de Brasília, p. 107-111. In: L. L. Leite \& C. H. Saito (Orgs), Contribuição ao conhecimento ecológico do cerrado. Brasília, Universidade de Brasília, V+325 p.

Morais, H. C.; I. R. Diniz \& D. M. S. SiLVA. 1999. Caterpillar seasonality in a central Brazilian cerrado. Revista de Biologia Tropical 47(4): $1025-1033$.

Pitkin, L. M. 2002. Neotropical ennomine moths: a review of the genera (Lepidoptera: Geometridae). Zoological Journal of the Linnean Society 135: 121-401.

Recebido em 10.I.2003; aceito em 30.X.2003 